\title{
Finite Element Analysis of a New Welding Structure of Cutter Mount in TBM
}

\author{
Dong ZHU¹, Kui CHEN², Xiao-Qi HUANG ${ }^{1}$, Nan HOU ${ }^{1}$, Wei-Zheng WANG ${ }^{1}$ \\ and Jun-Zhou HUO ${ }^{1}$
}

\author{
1. School of Mechanical Engineering, Dalian University of Technology, Dalian 116024, China \\ 2.State Key Laboratory of Shield Machine and Boring Technology Zhengzhou 450001, China \\ E-mail: 792022842@qq.com,707978612@qq.com, hounan123@mail.dlut.edu.cn, \\ wwz66@mail.dlut.edu.cn, huojunzhou@dlut.edu.cn
}

\begin{abstract}
Keywords: Tunnel boring machine, Cutter mount, New welding structure, Finite element analysis.
\end{abstract}
\begin{abstract}
TBM (Tunnel Boring Machine) has become a main technical means for the tunnel construction of rock condition. Cutter mount is an important welding structure on TBM cutter- head and it is the most dangerous positions to occur fatigue failure in the project. According to the characteristics that welding position of TBM cutter mount is easy to result in the fatigue fracture; a new cutter mount welding structure was designed on the basis of the damage positions of the cutter mount in practical engineering and the theory of welding structure design. Reduced-scale simplified models of existing service cutter mount welding structures and new cutter mount welding structure were established. Then, finite element analyses of the two reduced-scale simplified models were carried out and the results of finite element analysis for two kinds of reduced-scale simplified models were compared. The result shows that the area of compressive stress distribution of the new structure weld zone is larger than that of the existing service structure, the residual tensile stress is not conducive to the improvement of the fatigue performance of the structure and the compressive stress is favorable. Therefore, the new welding structure can effectively improve the fatigue performance of TBM cutter mount.
\end{abstract}

\section{Introduction}

TBM (Tunnel Boring Machine) is a highly mechanized and automated tunnel excavation equipment, as the key part of TBM, the cutter-head is large complex box welding structure [1]. In the long-term effect of the load, the cutter-head will appear fatigue crack and more than $70 \%$ of the cracks occur in the position of the weld lines, which will eventually lead to failure of the cutter-head and bring huge economic losses. Reasonable welding structure design can effectively improve the fatigue life of TBM cutter-head.

In the design of welding structure, different country introduce general technical standards, such as American Standard AWS [2], the International Welding Institute (IIW) standard XIII-1539-96/XV-845-96 [3]. Scholars have made some achievements in the research of welding structure. Different forms of welded joints and local details affect the distribution and size of residual stress $[4,5]$, the combined effects of residual stress and stress concentration at the notch have a significant effect on the fatigue life of welded structures. Ferrica and Branco [6] studied the effects of welding parameters on the fatigue properties of T-welded joints and conclude that the plate thickness and weld toe radius are the key factors that affect the fatigue properties of welded joints, fatigue strength and life span will decrease with increasing thickness. Lee Chin-Hyung et al. [7] studied the influence of the weld toe angle and toe radius on the fatigue life of the circular fillet weld non-bearing joint, it is concluded that the fatigue life of the welded joint is increased with the increase of the toe angle and the radius of the weld toe. Xuerong Zhao et al. [8] used finite element method to simulate the size and distribution of welding residual stress which provided theoretical basis for the formulation of correct welding process and improved the performance of the joint. The emphasis of anti-fatigue design of welded structure is to reduce the effect of stress concentration, so what really counts is to eliminate or reduce the stress concentration. 
In this paper, according to the welding structure, failure mode and working characteristics of the cutter mount in practical engineering; a new cutter mount welding structure is designed. Reduced-scale simplified models of existing service cutter mount welding structures and new cutter mount welding structure are established, then finite element analysis of the two reduced-scale simplified models are carried out, the two models of residual stress field are compared to verify the reliability of the new cutter mount.

\section{The Welding Structure and Reduced-Scale Simplified Models of Cutter Mount}

\section{The New Welding Structure of Cutter Mount}

The cutter mount is installed in hole of the cutter-head body through the welding method. Cutter mount assembly and the welding structure of the TBM in Jilin Water Diversion Project are shown in Fig. 1. From the structural point of view, the form of the weld is fillet weld.

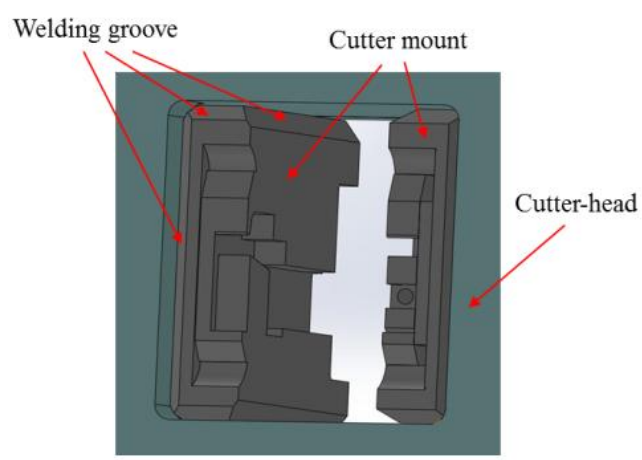

Fig. 1. Welded structure of Cutter Mount

The stress distribution of fillet weld is uneven, the stress concentration is larger, and the fatigue strength is lower, it is commonly used in the welding structure with low strength requirements. In this paper, based on the research background of cutter mount welding structure of TBM in Jilin Water Diversion Project, a new cutter mount welding structure in TBM is designed in order to improve the fatigue life of the welding structure. Existing service weld groove structure and the new structure is shown in Fig. 2. New welding structure mainly has made the improvement to the front of weld groove structure, the butt weld is used instead of the front fillet weld which is easy to occur fatigue failure.

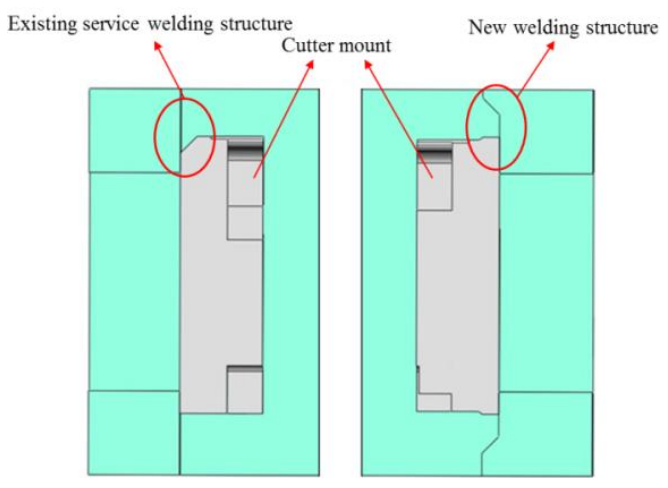

Fig. 2. Comparison between new welding structure and existing service welding structure of cutter mount

\section{A Reduced-Scale Simplified Model of Cutter Mount Welding Structure}

In order to conveniently analyze the welding residual stress field of cutter mount and predict the fatigue life, two kinds reduced-scale simplified model of cutter mount are designed. The two reduced-scale simplified models mainly reflect the front welding form of the cutter mount, and the influence of other weld lines is ignored. The size design of two reduced-scale simplified models is 
shown in Fig. 3(a). and Fig.3. (b).
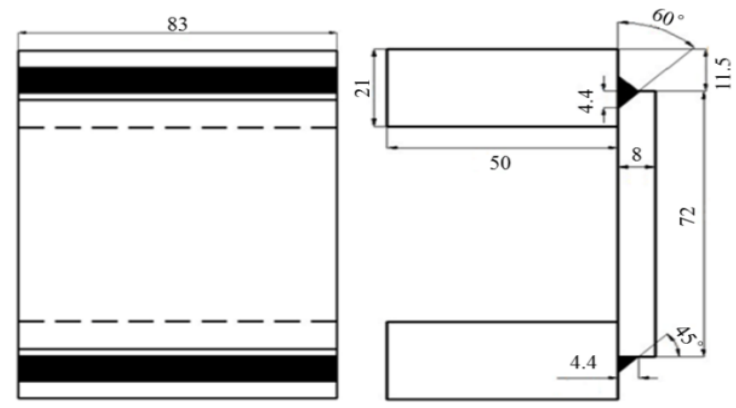

(a) simplified model of weld reduced-scale of existing service cutter mount
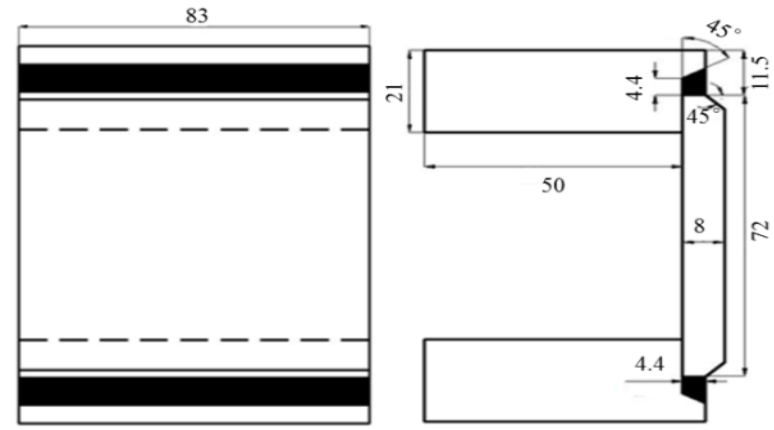

(b) simplified model of weld reduced-scale of new type tool apron

Fig. 3. Simplified model of welded reduced-scale Cutter Mount

The size of the weld line of the two kinds of welding structure is designed according to the equal strength principle [9]. The weld thickness of new structure reduced-scale model is $4.4 \mathrm{~mm}$, the size of two reduced-scale welding specimens model are shown in Fig. 3.

\section{Analysis on Residual Stress Field of Welding Reduced-Scale Model}

Before using ANSYS software to analyze residual stress, temperature field should be analyzed [10], then indirect method is used for the residual stress analysis. Welding process parameters is the same as the technological parameters of the actual cutter-head welding process, Gas Protective Welding is adopted. welding current is $225-286 \mathrm{~A}$, welding voltage is $24-32 \mathrm{~V}$, preheating temperature is $110^{\circ} \mathrm{C}$ $-180^{\circ} \mathrm{C}$, ER50-6 solid welding wire is used for welding and the diameter of welding wire is $1.2 \mathrm{~mm}$, welding efficiency: $\eta=0.75$, welding speed is $3 \mathrm{~mm} / \mathrm{s}$.

The Analysis of Residual Stress Field of the Reduced-Scale Model the Welding Structure about Existing Service Cutter Mount

The front of cutter-head in existing service has larger amount of weld line, as is shown in Fig. 3(a), the residual stress in the welding area is more complex, we only simulate and analysis the upper part of the structure. In the simulation, the welding process is divided into two welding beads, the thickness of the each weld bead is $4.4 \mathrm{~mm}$, the simplified structure and finite element model of weld line are shown in Fig. 4(a). and Fig 4. (b). 


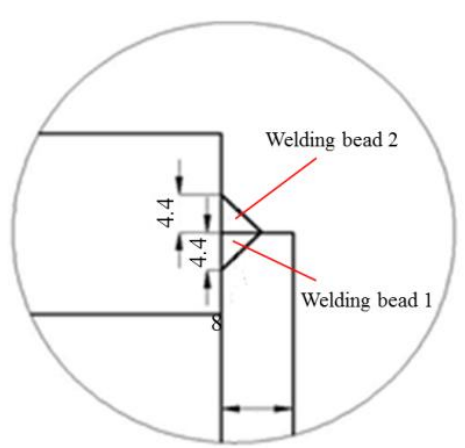

(a)Diagram of simplified analysis

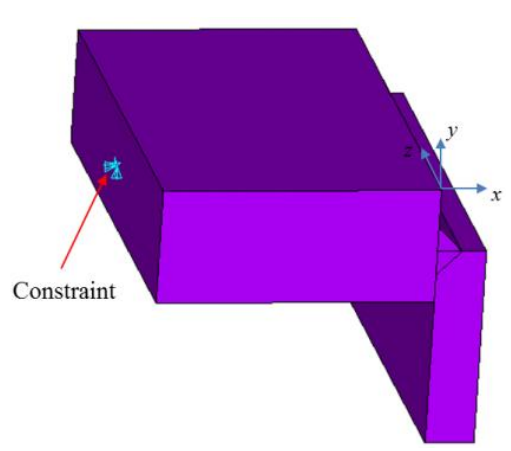

(b) Finite element analysis model

Fig 4. Simplified analytical model of current welded structure

The simulation process is as follow: the welding process of the first weld line is from $0.02 \mathrm{~s}$ to $27.687 \mathrm{~s}$, then the cooling time is $180 \mathrm{~s}$ to $207.69 \mathrm{~s}$; the welding process of the second weld line is from $207.87 \mathrm{~s}$ to $235.35 \mathrm{~s}$, cooling time is 3000 s to $3235.4 \mathrm{~s}$. After the analysis of temperature field, the thermal analysis is converted to structural analysis, displacement boundary condition in this analysis is shown in Fig. 4 (b). The constraint in $\mathrm{X}, \mathrm{Y}$ and $\mathrm{Z}$ directions are imposed only on one end face of the panel.

In order to study the distribution of residual stress along a specific path, 5 paths are set and the distribution and regularity of the stress parameters on the path are obtained. The path of the 1 and 2 is the weld toe line, path 3 is the bottom edge of the weld line, path 4 and path 5 are vertical of weld surface, The schematic diagram of stress path is shown in Fig. 5.

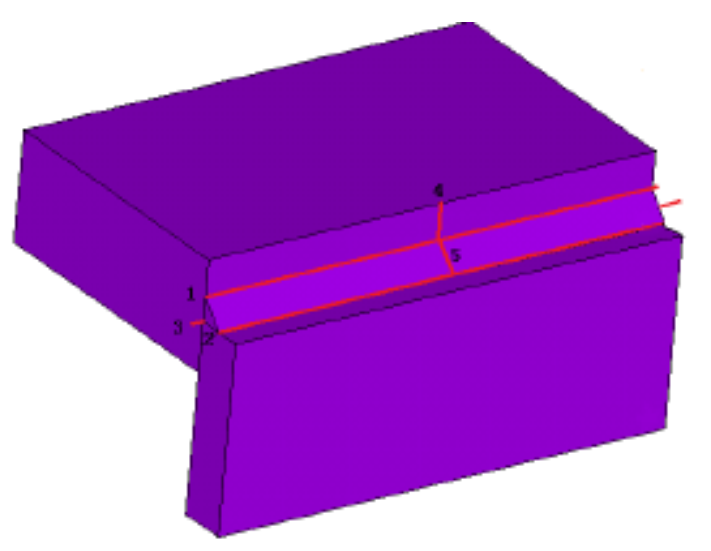

Fig. 5. Diagram of stress paths

The distribution curves of the stress components on the 5 paths are extracted, the stress curve of all paths are shown in Fig. 6.

Fig. 6(a) and Fig .6(b) reflect the distribution of stress parameters on the weld toe, it can be seen that the distribution of stress on the weld toe is similar, the equivalent residual stress in the weld is slightly smaller, slightly larger in the middle region, the equivalent residual stress is as high as $430 \mathrm{MPa}$ on the path 1 . Longitudinal residual stress $\sigma \mathrm{z}$ is the main component of residual stress. There generally exists tensile stress with in the length of the weld $10 \mathrm{~mm}-75 \mathrm{~mm}$, the mean value is $300 \mathrm{MPa}$, other areas of the weld is compressive stress. The transverse residual stress $\sigma \mathrm{x}$ and $\sigma \mathrm{y}$ is compressive stress at both ends of the weld lines and is tensile stress in the middle of the weld lines. The path 3 reflects the distribution of weld internal stress, the distribution of stress components along the weld perpendicular can be roughly seen as symmetrical, transverse residual stress distribution of $\sigma \mathrm{x}$ and $\sigma \mathrm{y}$ are similar along the weld lines which appear as compressive stress at the two ends of the weld lines and tensile stress in the middle of the weld. Path 4 shows that with the decrease of the distance to the weld line on the vertical face, every stress parameters are firstly increased and reach the maximum near the weld toe, it decreases until the weld toe. Path 5 shows the stress distribution on the Mid-perpendicular of weld path1 to path2, it can be seen that the 
transverse residual stress and longitudinal residual stress change in the same law. Two kinds of stress reach maximum in the intermediate region, the maximum value of transverse residual tensile stress reaches $300 \mathrm{MPa}$, and the longitudinal residual stress reaches $770 \mathrm{MPa}$, it can be known that this position is the dangerous point of the weld structure which can lead to crack generation and failure of the weld.

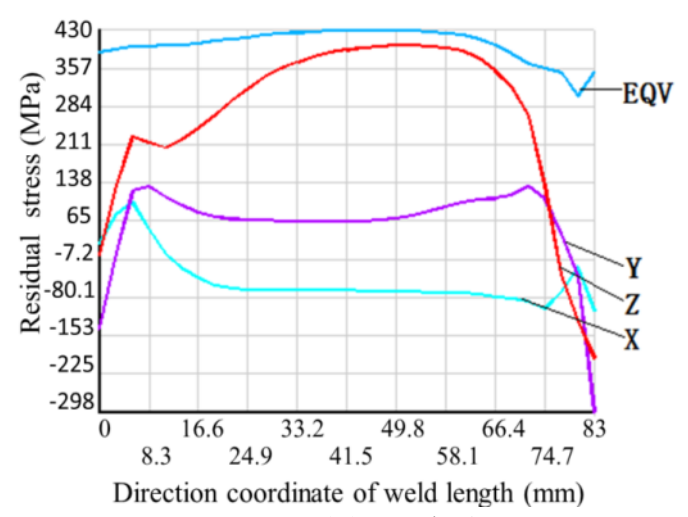

(a) Path 1

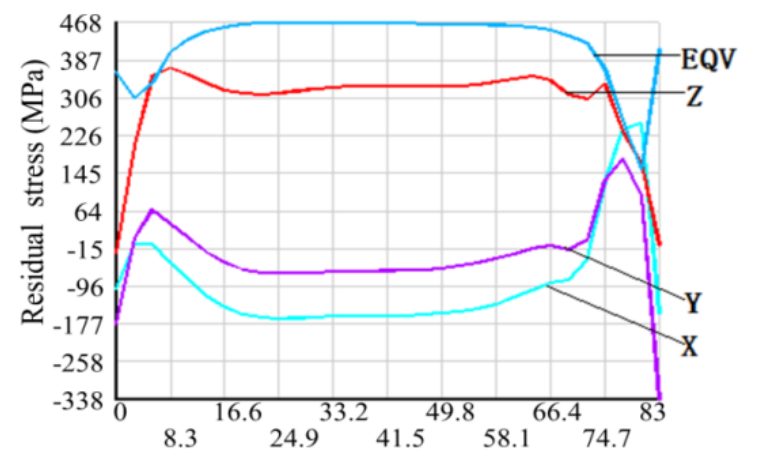

Direction coordinate of weld length $(\mathrm{mm})$

(c) path 3

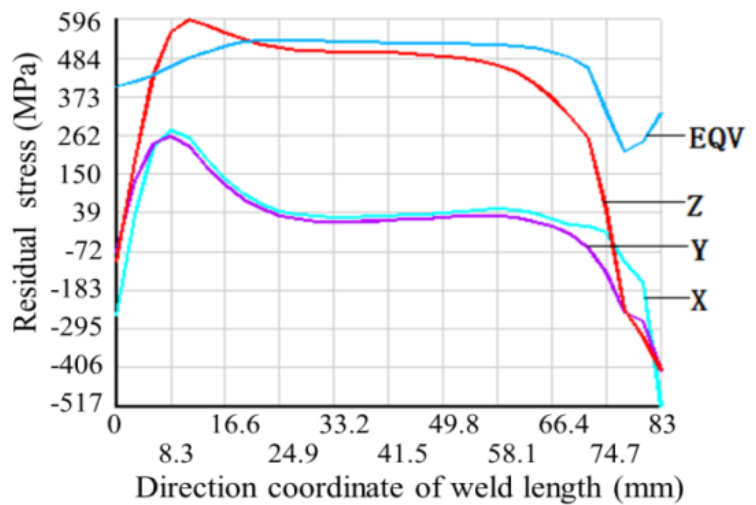

(b) path 2

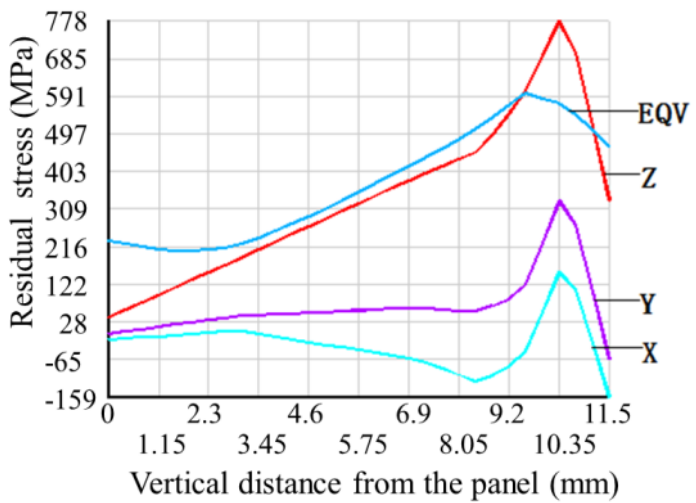

(d) path 4

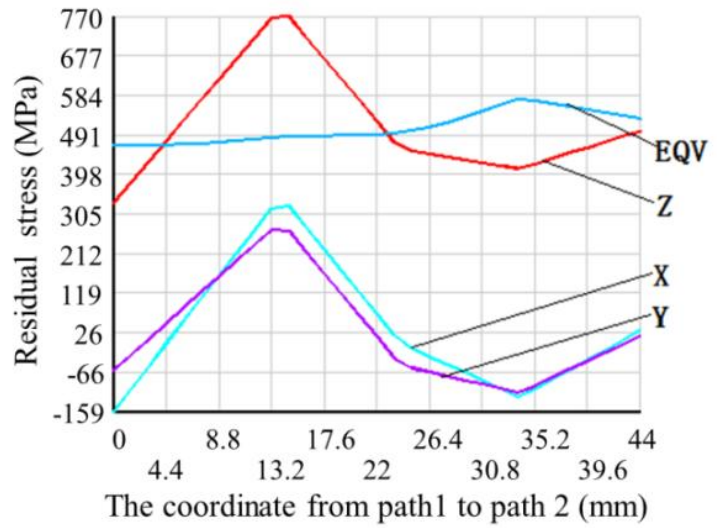

(e) path 5

Fig 6. Distribution curve of residual stress on paths

\section{The Analysis of Residual Stress Field about a New Welding Structure of Cutter Mount}

The method is the same as the analysis method of the welding structure in existing service cutter mount, only the upper part of the simplified mode about the new welding structure is considered. In the simulation, the welding process is divided into two welding beads, the actual shape of the single channel weld is not considered, the thickness of the 2 welding beads are $3 \mathrm{~mm}$ and $3.2 \mathrm{~mm}$. The simplified structure and finite element model of weld lines are shown in Fig. 7 (a) and Fig. 7 (b). 


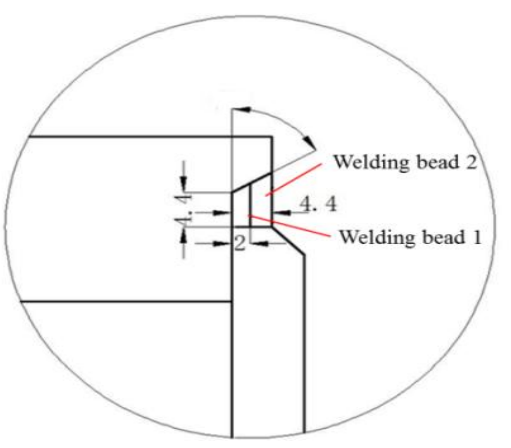

(a) Diagram of simplified analysis

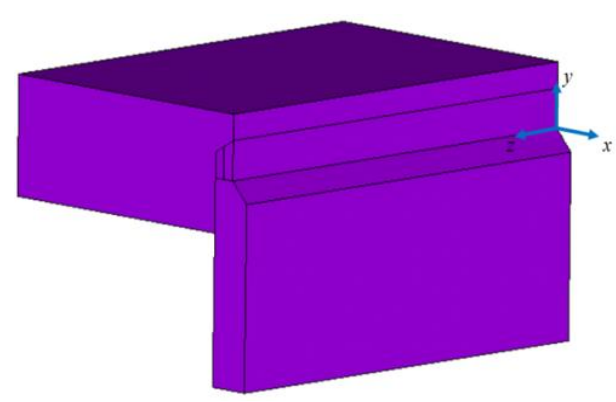

(b) Finite element analysis model

Fig. 7. Simplified analysis model of the new type of welded structure

The simulation process is as follows: the welding process of the first weld line is from $0.02 \mathrm{~s}$ to $27.687 \mathrm{~s}$, and then the cooling time is $180 \mathrm{~s}$ to $207.69 \mathrm{~s}$, the welding process of the second weld line is from $207.87 \mathrm{~s}$ to $235.35 \mathrm{~s}$, cooling time is $3000 \mathrm{~s}$ to $3235.4 \mathrm{~s}$. After the analysis of temperature field, the thermal analysis is converted to structural analysis, the displacement boundary in this analysis is the same as that of the existing service structure. The constraint in $\mathrm{X}, \mathrm{Y}$ and $\mathrm{Z}$ directions are imposed only on one end face of the panel.

Five paths are set to obtain the distribution and regularity of the stress parameters. Path 1 and 2 is the weld toe edge, path 3 and 4 is surface edge under welding bead, path 5 is the Midperpendicular of weld line surface, the direction of path 5 is from the weld toe edge to the cutter panel edge. The schematic diagram of stress path is shown in Fig. 8.

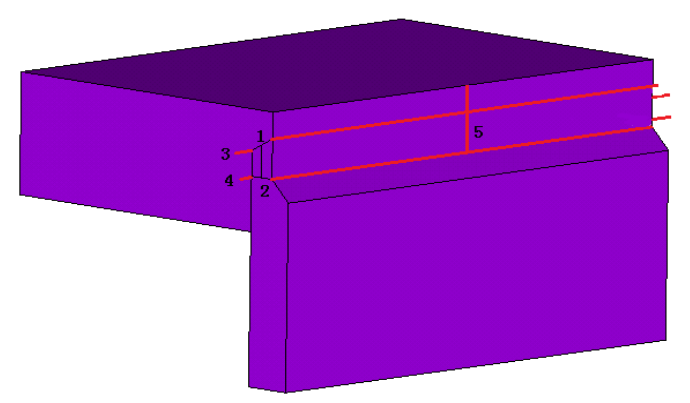

Fig. 8. Diagram of stress paths

The distribution curves of the stress components on the 5 paths are extracted and the stress curves of all paths are shown in Fig.9. It reflects the stress distribution parameters of weld toe line and the bottom line, the distribution of stress on the weld toe is similar, the equivalent residual stress oeqv and longitudinal residual stress $\sigma \mathrm{z}$ along the weld ends of the stress is less and the intermediate stress is more, the maximum equivalent stress is $415 \mathrm{MPa}$. The longitudinal residual stress $\sigma \mathrm{z}$ is the main component of residual stress. There generally exists tensile stress with in the length of the weld $10 \mathrm{~mm}-75 \mathrm{~mm}$, the maximum tensile stress on the weld toe is in the range of $360 \mathrm{MPa}-400 \mathrm{MPa}$, in other areas of the weld is compressive stress, maximum compressive stress reaches 180MPa. Transverse residual stress $\sigma y$ and Residual stress $\sigma x$ in the direction of weld depth increases at first and then decreases at length $7 \mathrm{~mm}$ and $75 \mathrm{~mm}$, the maximum stress remains stable in the range of $10-65 \mathrm{~mm}$. It can be concluded from the diagram that the transverse residual stress is mainly compressive stress on the weld toe, and the whole tensile stress level is below 50MPa. In the weld toe, the curve of $\sigma \mathrm{x}$ is above the curve of $\sigma \mathrm{y}$, but in the weld bottom edge, the curve of $\sigma \mathrm{x}$ below the curve of $\sigma y$. From the path 5 stress distribution situation, the longitudinal residual stress and the equivalent residual stress level in the weld zone are about $350 \mathrm{MPa}$, while transverse residual stress $\sigma y$ and residual stress in the direction of weld depth $\sigma x$ are compressive stress, the mean value of the compressive stress $\sigma \mathrm{y}$ is about $200 \mathrm{MPa}$, the compressive stress of $\sigma \mathrm{x}$ is slightly small and the average value is in the near of $800 \mathrm{MPa}$. 


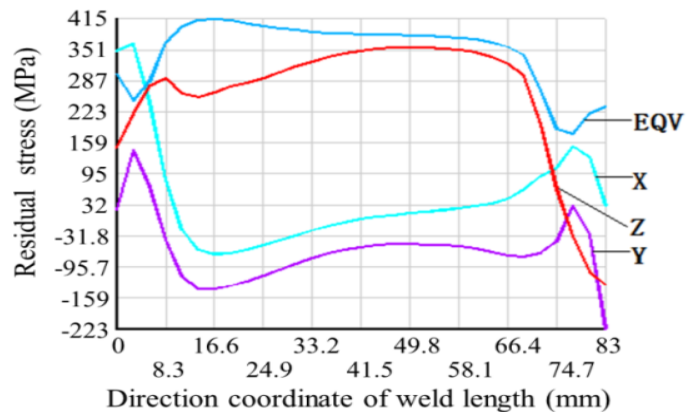

(a) path 1

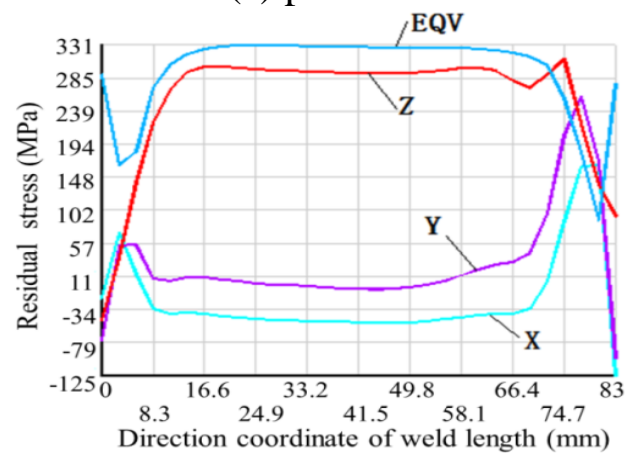

(c) path 3

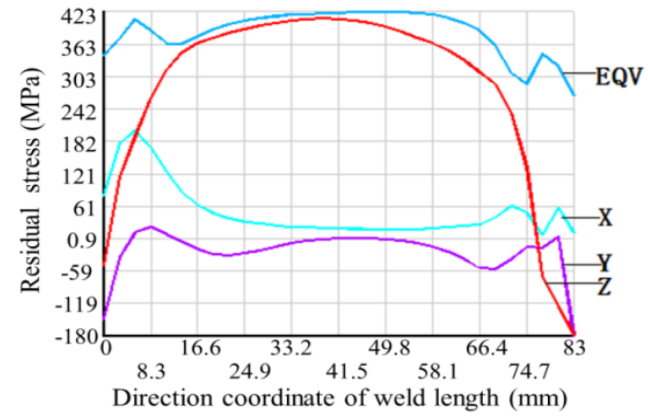

(b) path 2

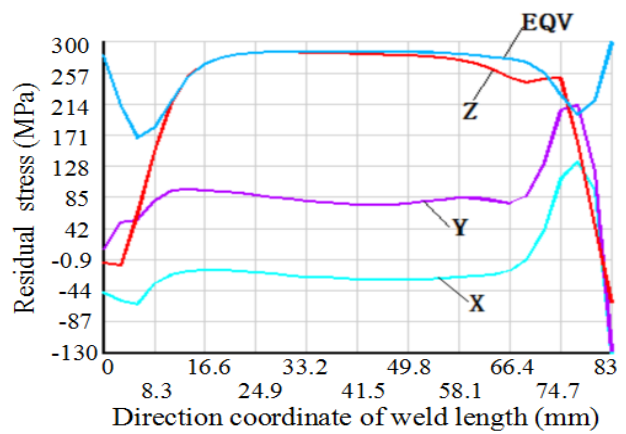

(d) path 4

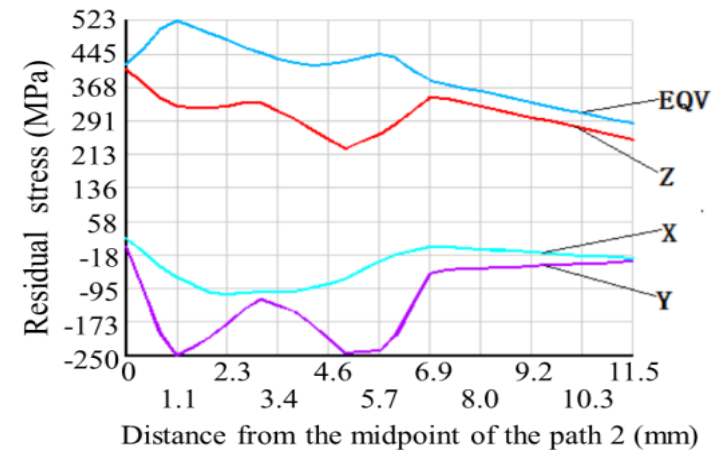

(e) path 5

Fig 9. Distribution curve of residual stress on paths

\section{Conclusion}

According to the comparison of residual stress between the two kinds of reduced-scale simplified model, results are shown as follows:

(1) For the equivalent residual stress, the equivalent residual stress of the weld line in the existing service structure is larger. The average equivalent residual stress of existing service structure is above $600 \mathrm{MPa}$ while the equivalent residual stress of the weld zone of the new structure is between 400-600 MPa, and it has a relatively large value near the weld toe.

(2) For the residual stress in $\mathrm{X}$ direction, it appears compressive stress in the weld zone of existing service structure which is about $500 \mathrm{MPa}$, the stress changes from compressive stress to tensile stress in the transition zone from the toe to the base material. The new structure of the weld zone is also a compressive stress, and it is slightly smaller than that of the existing service structure and reaches about $450 \mathrm{MPa}$, but the area near the weld toe of base material is also presented as a compressive stress. In addition, the distribution of the residual stress in the $\mathrm{X}$ direction along the new structure is more uniform.

(3) For the residual stress in $\mathrm{Y}$ direction, it appears compressive stress in the weld zone of existing service structure which is about $300 \mathrm{MPa}$, the stress changes from compressive stress to tensile stress in the transition zone from the toe to the base material, the tensile stress value is about $100 \mathrm{MPa}$. The weld zone of new structure also appears compressive stress which is larger than that of 
the existing service structure and reaches $500 \mathrm{MPa}$, the area near the weld toe of base material is also presented as a compressive stress, its value is about 200MPa. The Y direction stress along the new structure welding toe is also smaller.

(4) For the residual stress in $\mathrm{Z}$ direction, The stress distribution characteristics of the two kinds of structures are similar, but the tensile stress at the weld toe of the existing service structure is larger and reaches $485 \mathrm{MPa}$, the tensile stress is smaller at the middle of weld line and reaches about $100 \mathrm{MPa}$, the compressive stress at both ends of the weld line is about $150 \mathrm{MPa}$. The tensile stress at the toe of the new structure is slightly smaller and reaches about $400 \mathrm{MPa}$ which is changed to compressive stress at the center and two ends of the weld line, the value is about $300 \mathrm{MPa}$.

In summary, the value of tensile stress of existing service structure is larger than that of the new structure, the tensile stress distribution area of the existing service structure weld zone is larger than that of the new structure. But the compressive stress distribution area of the new structure weld zone is larger than that of the existing service structure. The residual tensile stress is not conducive to the improvement of the fatigue performance and the compressive stress is favorable, so the new welding structure is more favorable to the fatigue property of the weld line in TBM cutter-head.

\section{Acknowledgments}

This work is supported by the National Natural Science Foundation of China (Grant No.51375001), National Key Technologies R \& D Program of Liaoning Province (Grant No. 2015106016), the Fundamental Research Funds for the Central Universities (Grant No. DUT16QY11) and Development Program of China (973 Program) (Granted No.2013CB035402).

\section{Reference:}

1. Ling J, Sun W, Huo J, Guo L.. Study of tbm cutterhead fatigue crack propagation life based on multi-degree of freedom coupling system dynamics. [J]Computers \& Industrial Engineering, 83, 1-14. (2015)

2. American Welding Society. Committee on Structural Welding. Structural welding code-steel[M] . (1983)

3. HOBBACHER A. Fatigue design of welded joints and components [M]. (1996).

4. BALASUBRAMANIAN V, GUHA B. Analyzing the influences of weld size on fatigue life prediction of FCAW cruciform joints by strain energy concept $[\mathrm{J}]$. International Journal of Pressure Vessels \& Piping, 1999, 76(76): 759-768.

5. Chaowen Li, Yong Wang, Tao Han. Effect of welding sequence on residual stress and deformation of $T$ joint $[\mathrm{J}]$. Welding journal,32(10):37-40, (2011).

6. FERRIA J A, BRANCO C M. Fatigue Analysis and Prediction in Filled Welded Joints in the Low Thickness Range[J]. Journal of Fatigue\& Fracture of Engineering Materials and Structures, 13(3):201-212, (1990).

7. CHIN-HYUNG L, KYONG-HO C, GAB-CHUL J, et al. Effect of weld geometry on the fatigue life of non-load-carrying fillet welded cruciform joints[J]. Engineering Failure Analysis, 16(3): 849-855, (2009).

8. Xuerong Zhao, Yuanxiang Zhu, Qinming Sun. The finite element analysis of the residual stress in the butt welding line $[\mathrm{J}]$. Welding technology, 32(5):14-15, (2003).

9. Zuyan Shen, Yangji Chen, Yiyi Chen. Basic principles of steel structure[M]. Beijing: China Building Industry Press, (2005).

10. Bai Q, Ye Z, Sun W. Welding Temperature Field and Stress Field Using Finite Element Model[J]. Journal of Convergence Information Technology, 7(19):68-76, (2012). 